\title{
Dominator Coloring of Central Graphs
}

\author{
K. Kavitha \\ Research Scholar \\ Department of Mathematics, Madras Christian \\ College Chennai - 600059
}

\begin{abstract}
Dominator chromatic number of central graph of various graph families such as cycles, paths, wheel graphs, complete graphs and complete bipartite graphs are found in this paper. Also these parameters are compared with dominator chromatic number of their respective graph families.
\end{abstract}

Key words: Central graph, dominator coloring.

\section{AMS Subject Classification: 05C15, $05 \mathrm{C} 69$}

\section{PRELIMINARIES}

The notion of central graph and dominator coloring are reviewed in this section $[1,2,3,4]$.

\section{Definition 1.1}

Let $\mathrm{G}$ be a simple and undirected graph and let its vertex set and edge set be denoted by $\mathrm{V}(\mathrm{G})$ and $\mathrm{E}(\mathrm{G})$. The central graph of $\mathrm{G}$, denoted by $\mathrm{C}(\mathrm{G})$ is obtained by subdividing each edge of $\mathrm{G}$ exactly once and joining all the non-adjacent vertices of $G$ in $C(G)$.

\section{Definition 1.2}

A proper coloring of a graph $\mathrm{G}$ is an assignment of colors to the vertices of $\mathrm{G}$ in such a way that no two adjacent vertices receive the same color. The chromatic number $\chi(\mathrm{G})$, is the minimum number of colors required for a proper coloring of G. A Color class is the set of all vertices, having the same color. The color class corresponding to the color $\mathrm{i}$ is denoted by $\mathrm{V}_{\mathrm{i}}$.

\section{Definition 1.3}

A dominator coloring of a graph $\mathrm{G}$ is a proper coloring in which every vertex of $\mathrm{G}$ dominates every vertex of at least one color class. The convention is that if $\{\mathrm{v}\}$ is a color class, then $\mathrm{v}$ dominates the color class $\{\mathrm{v}\}$. The dominator chromatic number $\chi_{\mathrm{d}}(\mathrm{G})$ is the minimum number of colors required for a dominator coloring of $\mathrm{G}$.

\section{DOMINATOR CHROMATIC NUMBER OF CENTRAL GRAPHS}

Dominator chromatic number of Central graph of various classes of graphs is obtained in this section.

\section{Theorem 2.1}

For cycle graph $\mathrm{C}_{\mathrm{n}}$ of order $\mathrm{n} \geq 3$, $\chi_{\mathrm{d}}\left[\mathrm{C}\left(\mathrm{C}_{\mathrm{n}}\right)\right]= \begin{cases}\lceil 2 \mathrm{n} / 3\rceil+2 & \text { when } \mathrm{n}=3 \\ \lceil 2 \mathrm{2} / 3\rceil+1 & \text { otherwise }\end{cases}$

\author{
N.G. David \\ Associate Professor \\ Department of Mathematics, Madras Christian \\ College, Chennai - 600059
}

\section{Proof}

Let $C_{n}$ be the cycle graph of order $n \geq 3$ and let $V\left(C_{n}\right)=\left\{v_{1}\right.$, $\left.\mathrm{v}_{2}, \ldots, \mathrm{v}_{\mathrm{n}}\right\}$ and $\mathrm{E}\left(\mathrm{C}_{\mathrm{n}}\right)=\left\{\mathrm{e}_{1}, \mathrm{e}_{2}, \ldots, \mathrm{e}_{\mathrm{n}}\right\}$, where $\mathrm{e}_{\mathrm{i}}=\mathrm{v}_{\mathrm{i}} \mathrm{v}_{\mathrm{i}+1}, 1 \leq \mathrm{i} \leq$ $\mathrm{n}-1$ and $\mathrm{e}_{\mathrm{n}}=\mathrm{v}_{\mathrm{n}} \mathrm{v}_{1}$. By the definition of central graph, $\mathrm{C}\left(\mathrm{C}_{\mathrm{n}}\right)$ is obtained by subdividing each edge $\mathrm{v}_{\mathrm{i}} \mathrm{v}_{\mathrm{i}+1}$, $1 \leq \mathrm{i} \leq \mathrm{n}-1$ of $\mathrm{C}_{\mathrm{n}}$ exactly once by newly added vertex $\mathrm{c}_{\mathrm{i}}$, and subdividing $\mathrm{v}_{\mathrm{n}} \mathrm{v}_{1}$ by $\mathrm{c}_{\mathrm{n}}$ and joining $\mathrm{v}_{\mathrm{i}}$ with $\mathrm{v}_{\mathrm{j}}, 1 \leq \mathrm{i}, \mathrm{j} \leq \mathrm{n}, \mathrm{i} \neq \mathrm{j}$ and $\mathrm{v}_{\mathrm{i}} \mathrm{v}_{\mathrm{j}} \notin \mathrm{E}\left(\mathrm{C}_{\mathrm{n}}\right)$. Let $\mathrm{v}_{1}=\left\{\begin{array}{llll}\mathrm{v}_{1}, & \mathrm{v}_{2}, & \ldots, & \mathrm{v}_{\mathrm{n}}\end{array}\right\}$ and $\mathrm{V}_{2}=\left\{\mathrm{c}_{1}, \mathrm{c}_{2}, \ldots, \mathrm{c}_{\mathrm{n}}\right\}$. Then $\mathrm{V}\left(\mathrm{C}\left(\mathrm{C}_{\mathrm{n}}\right)\right)=\mathrm{V}_{1} \cup \mathrm{V}_{2}$.

The following procedure gives a dominator coloring of $\mathrm{C}\left(\mathrm{C}_{\mathrm{n}}\right)$. Since all newly added vertices $c_{i}, 1 \leq i \leq n$ in $C\left(C_{n}\right)$ form an independent set, color these vertices by color 1 . When $n=3 k$, $\mathrm{k} \geq 2, \quad$ the vertices $\mathrm{v}_{\mathrm{i}}$ and $\mathrm{v}_{\mathrm{i}+1}$, $\mathrm{i}=1,4,7, \ldots,(\mathrm{n}-2)$ are colored by color $2\lceil\mathrm{i} / 3\rceil$ and the remaining vertices $v_{j,} j=3,6,9, \ldots, n$ are colored by $1+(2 j / 3)$. When $\mathrm{n}=3 \mathrm{k}-1, \mathrm{k} \geq 2$, the vertices $\mathrm{v}_{\mathrm{i}}$ and $\mathrm{v}_{\mathrm{i}+1}$, $\mathrm{i}=1,4,7, \ldots,(\mathrm{n}-4)$ are colored by color $2\lceil\mathrm{i} / 3\rceil$ and the remaining vertices $v_{j}, j=3,6,9, \ldots,(n-2)$ are colored by color $1+(2 j / 3)$ and $v_{n-1}$ and $v_{n}$ are colored by $\lceil 2 n / 3\rceil$ and $\lceil 2 n / 3\rceil+1$. When $\mathrm{n}=3 \mathrm{k}+1, \mathrm{k} \geq 2$, the vertices $\mathrm{v}_{\mathrm{i}}$ and $\mathrm{v}_{\mathrm{i}+1}, \mathrm{i}=1,4,7, \ldots$, $(\mathrm{n}-3)$ are colored by color $2\lceil\mathrm{i} / 3\rceil$ and the remaining vertices $\mathrm{v}_{\mathrm{j}}$, $\mathrm{j}=3,6,9, \ldots, \mathrm{n}-1$ are colored by $1+(2 \mathrm{j} / 3)$ for and $\mathrm{v}_{\mathrm{n}}$ is colored by $\lceil 2 n / 3\rceil+1$. When $n=3$, the vertex $v_{i}$ is colored by color $i+1,1 \leq i \leq 3$. When $n=4$, the vertices $v_{i}$ are colored by the color sequence $(2,2,3,4)$.

The vertices $v_{i}$ and $v_{i+1}, i=1,4,7, \ldots$ dominate one of the color classes of $v_{j}, j=3,6,9, \ldots$ The vertex $v_{j}$, $\mathrm{j}=3,6,9, \ldots$ dominates itself. The center vertices $c_{i}, i=1,4$, $7, \ldots$ dominate the color class of $v_{i}$. The center vertices $c_{i}$ and $\mathrm{c}_{\mathrm{i}+1}, \mathrm{i}=2,5,8, \ldots$ dominate the color class of $\mathrm{v}_{\mathrm{i}+1}$, as they are adjacent to $\mathrm{v}_{\mathrm{i}+1}$. When $\mathrm{n}=3$, it is easy to see that $\chi_{\mathrm{d}}\left[\mathrm{C}\left(\mathrm{C}_{3}\right)\right]=\lceil 2 \mathrm{n} / 3\rceil+2$ and when $\mathrm{n}=4$, it is seen that $\chi_{\mathrm{d}}\left[\mathrm{C}\left(\mathrm{C}_{4}\right)\right]=\lceil 2 \mathrm{n} / 3\rceil+1$.

Hence $\chi_{d}\left[C\left(C_{n}\right)\right]= \begin{cases}{[2 n / 3\rceil+2} & \text { when } n=3 \\ \lceil 2 n / 3\rceil+1 & \text { otherwise }\end{cases}$

The following example illustrates the procedure discussed in the above result.

\section{Example 2.2}

In figure 1 , central graph of $\mathrm{C}_{7}$ is depicted with a dominator coloring. 


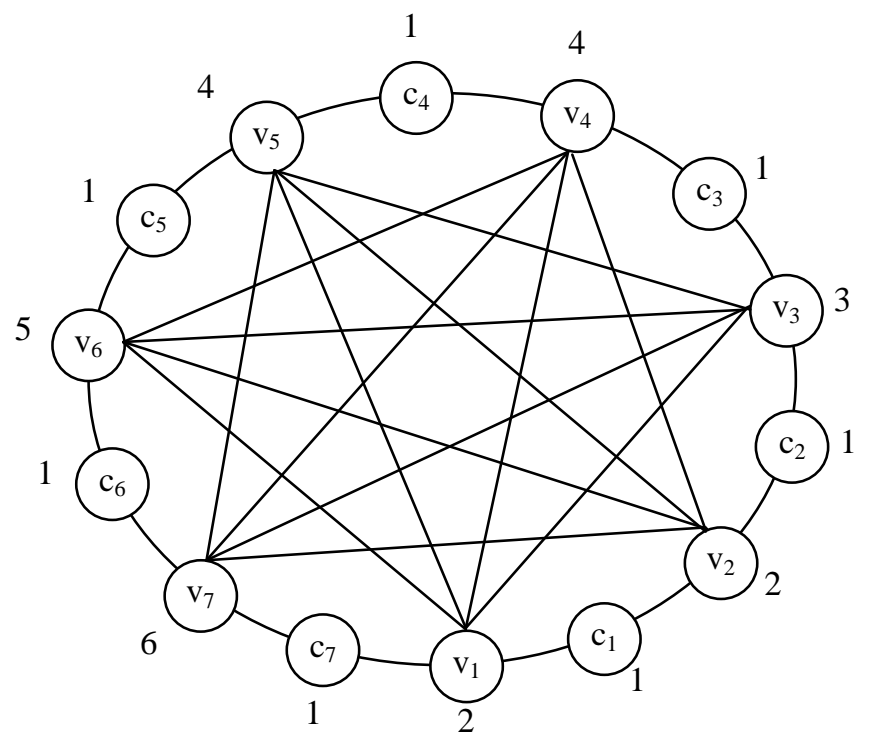

Figure 1

The color classes of $\mathrm{C}\left(\mathrm{C}_{7}\right)$ are, $\mathrm{V}_{1}=\left\{\mathrm{c}_{1}, \mathrm{c}_{2}, \mathrm{c}_{3}, \mathrm{c}_{4}, \mathrm{c}_{5}, \mathrm{c}_{6}, \mathrm{c}_{7}\right\}, \mathrm{V}_{2}=\left\{\mathrm{v}_{1}, \mathrm{v}_{2}\right\}, \mathrm{V}_{3}=\left\{\mathrm{v}_{3}\right\}$, $\mathrm{V}_{4}=\left\{\mathrm{v}_{4}, \mathrm{v}_{5}\right\}, \mathrm{V}_{5}=\left\{\mathrm{v}_{6}\right\}$ and $\mathrm{V}_{6}=\left\{\mathrm{v}_{7}\right\}$. The dominator chromatic number is, $\chi_{\mathrm{d}}\left[\mathrm{C}\left(\mathrm{C}_{7}\right)\right]=6$.

\section{Theorem 2.3}

For path graph $P_{n}$ of order $n \geq 2$, $\chi_{\mathrm{d}}\left[\mathrm{C}\left(\mathrm{P}_{\mathrm{n}}\right)\right]= \begin{cases}\lceil\mathrm{n} / 2\rceil+1 & \text { when } \mathrm{n} \text { is odd } \\ \lceil\mathrm{n} / 2\rceil+2 & \text { when } \mathrm{n} \text { is even }\end{cases}$

\section{Proof}

Let $\mathrm{P}_{\mathrm{n}}$ be a path of order $\mathrm{n} \geq 3$ and let $\mathrm{V}\left(\mathrm{P}_{\mathrm{n}}\right)=\left\{\mathrm{v}_{1}, \mathrm{v}_{2}, \ldots, \mathrm{v}_{\mathrm{n}}\right\}$. The central graph $\mathrm{C}\left(\mathrm{P}_{\mathrm{n}}\right)$ is obtained by subdividing each edge $\mathrm{v}_{\mathrm{i}} \mathrm{V}_{\mathrm{i}+1}, 1 \leq \mathrm{i} \leq \mathrm{n}-1$ of $\mathrm{P}_{\mathrm{n}}$ exactly once by adding a new vertex $c_{i}$ in $C\left(P_{n}\right)$ and joining each vertex $v_{j}$, $1 \leq \mathrm{j} \leq \mathrm{n}-2$ with each vertex $\mathrm{v}_{\mathrm{k}}, \mathrm{j}+2 \leq \mathrm{k} \leq \mathrm{n}$. Let $\mathrm{V}_{1}=\left\{\mathrm{v}_{1}, \mathrm{v}_{2}, \ldots, \mathrm{v}_{\mathrm{n}}\right\}$ and $\mathrm{V}_{2}=\left\{\mathrm{c}_{1}, \mathrm{c}_{2}, \ldots, \mathrm{c}_{\mathrm{n}-1}\right\}$. Then $\mathrm{V}\left(\mathrm{C}\left(\mathrm{P}_{\mathrm{n}}\right)\right)=\mathrm{V}_{1} \cup \mathrm{V}_{2}$. Relabel the vertices of $\mathrm{C}\left(\mathrm{P}_{\mathrm{n}}\right)$ by $\mathrm{u}_{1}=\mathrm{v}_{1}$, $\mathrm{u}_{2}=\mathrm{c}_{1}, \mathrm{u}_{3}=\mathrm{v}_{2}, \ldots, \mathrm{u}_{2 \mathrm{n}-1}$ consecutively.

The following procedure gives a dominator coloring of $\mathrm{C}\left(\mathrm{P}_{\mathrm{n}}\right)$. When $\mathrm{n} \geq 6$, the vertex $\mathrm{u}_{1}$ is colored by color $1, \mathrm{u}_{2}$ is colored by color 2 and the vertex $u_{i}, i=4,6,8, \ldots, 2 n-2$ is colored by color 1 . If $n$ is odd, the vertex $u_{i}, i=5,9,13, \ldots, 2 n-1$ is colored by color 2 and the vertices $u_{j}, j=3,7,11, \ldots, 2 n-3$ are respectively colored by individual colors $3,4,5, \ldots$, $\lceil\mathrm{n} / 2\rceil+1$. If $\mathrm{n}$ is even, the vertex $u_{i}, \mathrm{i}=5,9,13, \ldots, 2 \mathrm{n}-3$ is colored by color 2 and the vertices $u_{j}, j=3,7,11, \ldots, 2 n-1$ are colored respectively by individual colors $3,4,5, \ldots$, $\lceil\mathrm{n} / 2\rceil+2$. When $\mathrm{n}=3,4$ or 5 , the vertices of $\mathrm{C}\left(\mathrm{P}_{\mathrm{n}}\right)$ are colored by the color sequences $(1,2,1,3,2),(1,2,3,1,2,4,2)$ or $(1,2,3,1,2,1,4,2,1)$ in order to get a dominator coloring.

When $\mathrm{n} \geq 6$, the vertex $\mathrm{u}_{1}$ dominates the color class of $\mathrm{u}_{7}$. If $\mathrm{n}$ is odd, vertices $u_{i}$ and $u_{i+2}, i=2,6,10,14, \ldots, 2 n-3$ dominate the color class of $u_{i+1}$. The vertex $u_{j}$, for $j=3,7,11, \ldots, 2 n-3$ dominates itself. If $n$ is even, vertices $u_{i}$ and $u_{i+2}, i=2,6,10,14, \ldots, 2 n-6$ dominate the color class of $\mathrm{u}_{\mathrm{i}+1}$ and $\mathrm{u}_{2 \mathrm{n}-2}$ dominates the color class of $\mathrm{u}_{2 \mathrm{n}-1}$. The vertex $\mathrm{u}_{\mathrm{j}}$, for $\mathrm{j}=3,7,11, \ldots, 2 \mathrm{n}-3$ dominates itself. The vertex $\mathrm{u}_{\mathrm{j}}$, for $\mathrm{j}=5,9,13, \ldots, 2 \mathrm{n}-1$ dominate either $\mathrm{u}_{\mathrm{j}+6}, \mathrm{u}_{\mathrm{j}-6}$ or both.

Hence $\chi_{d}\left[C\left(P_{n}\right)\right]= \begin{cases}\lceil n / 2\rceil+1 & \text { when } n \text { is odd } \\ \lceil\mathrm{n} / 2\rceil+2 & \text { when } n \text { is even }\end{cases}$

The following example illustrates the procedure discussed in the above result.

\section{Example 2.4}

In figure 2, central graph of $\mathrm{P}_{6}$ is depicted with a dominator coloring.

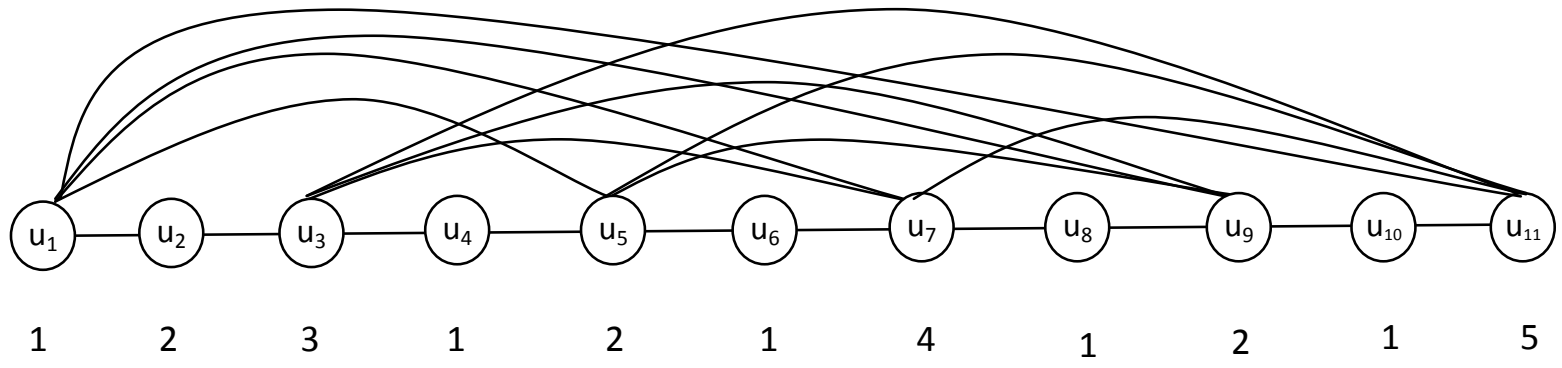

Figure 2

The color classes of $\mathrm{C}\left(\mathrm{P}_{6}\right)$ are, $\mathrm{V}_{1}=\left\{\mathrm{u}_{1}, \mathrm{u}_{4}, \mathrm{u}_{6}, \mathrm{u}_{8}, \mathrm{u}_{10}\right\}, \mathrm{V}_{2}=\left\{\mathrm{u}_{2}, \mathrm{u}_{5}, \mathrm{u}_{9}\right\}, \mathrm{V}_{3}=\left\{\mathrm{u}_{3}\right\}, \mathrm{V}_{4}=\left\{\mathrm{u}_{7}\right\}, \mathrm{V}_{5}=\left\{\mathrm{u}_{11}\right\}$. The dominator chromatic number is, $\chi_{\mathrm{d}}\left[\mathrm{C}\left(\mathrm{P}_{6}\right)\right]=5$.

\section{Proof}

\section{Theorem 2.5}

For wheel graph $\mathrm{W}_{1, \mathrm{n}}$ of order $\mathrm{n} \geq 3$,

$$
\chi_{\mathrm{d}}\left[\mathrm{C}\left(\mathrm{W}_{1, \mathrm{n}}\right)\right]= \begin{cases}\lceil 2 \mathrm{n} / 3\rceil+3 & \text { when } \mathrm{n}=3 \\ \lceil 2 \mathrm{n} / 3\rceil+2 & \text { otherwise }\end{cases}
$$

Let $W_{1, n}$ be a wheel graph of order $n \geq 3$. Let the vertex at the centre be $\mathrm{v}_{1}$ and the vertices on the rim be $\mathrm{v}_{2}, \mathrm{v}_{3}, \ldots, \mathrm{v}_{\mathrm{n}+1}$. Central graph $\mathrm{C}\left(\mathrm{W}_{1,}\right)$ is obtained by subdividing each edge of $W_{1, n}$ exactly once and join all the non-adjacent vertices of $\mathrm{W}_{1, \mathrm{n}}$. Let the middle vertices on the edges $\mathrm{v}_{1} \mathrm{v}_{\mathrm{i}}, \mathrm{i}=2, \ldots, \mathrm{n}+1$ of $\mathrm{W}_{1, \mathrm{n}}$ be $\mathrm{c}_{\mathrm{i}-1}$ and the middle 
vertices on $\mathrm{v}_{\mathrm{i}} \mathrm{v}_{\mathrm{i}+1}, \mathrm{i}=2, \ldots, \mathrm{n}$ of $\mathrm{W}_{1, \mathrm{n}}$ be $\mathrm{c}_{\mathrm{n}+\mathrm{i}-1}$ and the middle vertex on $\mathrm{v}_{\mathrm{n}+1} \mathrm{v}_{2}$ be $\mathrm{c}_{2 \mathrm{n}}$.

A dominator coloring of $\mathrm{C}\left(\mathrm{W}_{1, \mathrm{n}}\right)$ is obtained by the following procedure. Color the vertex $\mathrm{v}_{1}$ by color 1 and assign color 2 to the center vertices $c_{i}, 1 \leq i \leq 2 n$, as they form an independent set. When $\mathrm{n}=3 \mathrm{k}, \mathrm{k} \geq 2$, the vertices $\mathrm{v}_{\mathrm{i}}$ and $\mathrm{v}_{\mathrm{i}+1}$, for $\mathrm{i}=2,5,8, \ldots,(\mathrm{n}-1)$ are colored by color $1+\lceil 2 \mathrm{i} / 3\rceil$ and the remaining vertices $\mathrm{v}_{\mathrm{j}}$, for $\mathrm{j}=4,7,10, \ldots,(\mathrm{n}+1)$ are colored by color $2+\lfloor 2 j / 3\rfloor$. When $n=3 k-1, k \geq 2$, the vertices $v_{i}$ and $v_{i+1}$, for $i=2,5,8, \ldots,(n-3)$ are colored by color $1+\lceil 2 \mathrm{i} / 3\rceil$ and the remaining vertices $v_{j}$ for $j=4,7,10, \ldots,(n-1)$ are colored by color $2+\lfloor 2 \mathrm{j} / 3\rfloor$ and the vertices $\mathrm{v}_{\mathrm{n}}$ and $\mathrm{v}_{\mathrm{n}+1}$ are colored respectively by colors $\lceil 2 \mathrm{n} / 3\rceil+1$ and $\lceil 2 \mathrm{n} / 3\rceil+2$. When $\mathrm{n}=3 \mathrm{k}+1, \mathrm{k} \geq 2$, the vertices $\mathrm{v}_{\mathrm{i}}$ and $\mathrm{v}_{\mathrm{i}+1}$, for $\mathrm{i}=2,5,8, \ldots,(\mathrm{n}-2)$ are colored by color $1+\lceil 2 \mathrm{i} / 3\rceil$ and the remaining vertices $\mathrm{v}_{\mathrm{j}}$, for $\mathrm{j}=4,7,10, \ldots, \mathrm{n}$ are colored by color $2+\lfloor 2 j / 3\rfloor$ and the vertex $v_{n+1}$ is colored by color $\lceil 2 n / 3\rceil+2$. When $n=3, v_{i}$ is colored by color $i+1,2 \leq i \leq 4$. When $\mathrm{n}=4, \mathrm{v}_{\mathrm{i}}$ and $\mathrm{v}_{\mathrm{i}+1}$ is colored by color $\mathrm{i}+1, \mathrm{i}=2$ and remaining vertices $\mathrm{v}_{\mathrm{i}}$ are colored by color $\mathrm{i}, \mathrm{i}=4$ and 5 .

The vertex $v_{1}$ and vertices $v_{i}, i=4,7,10, \ldots$ of $C\left(W_{1, n}\right)$, dominate themselves. The vertices $v_{i}$ and $v_{i+1}$, $\mathrm{i}=2,5,8, \ldots$ dominate the color class of $\mathrm{v}_{\mathrm{i}+2}$. The center vertices $\mathrm{c}_{\mathrm{i}}, 1 \leq \mathrm{i} \leq \mathrm{n}$ dominate the color class of $\mathrm{v}_{1}$. The center vertices on the rim $c_{i}$ and $c_{i+1}, i=n+2, n+5, n+8, \ldots$ dominate the color class of $v_{i-n+2}$ and the center vertices on the rim $c_{i}$, $\mathrm{i}=\mathrm{n}+1, \mathrm{n}+4, \mathrm{n}+7, \ldots$ dominate the color class of $\mathrm{v}_{\mathrm{i}-\mathrm{n}+1}$. When $\mathrm{n}=3$, it is easy to see that $\chi_{\mathrm{d}}\left[\mathrm{C}\left(\mathrm{W}_{1,3}\right)\right]=\lceil 2 \mathrm{n} / 3\rceil+3$ and when $\mathrm{n}=4$, it is seen that $\chi_{\mathrm{d}}\left[\mathrm{C}\left(\mathrm{W}_{1,4}\right)\right]=\lceil 2 \mathrm{n} / 3\rceil+2$.

Hence $\chi_{d}\left[C\left(W_{1, n}\right)\right]= \begin{cases}\lceil 2 n / 3\rceil+3 & \text { when } n=3 \\ \lceil 2 n / 3\rceil+2 & \text { otherwise }\end{cases}$

The following example illustrates the procedure discussed in the above result.

\section{Example 2.6}

In figure 3, central graph of $\mathrm{w}_{1,5}$ is depicted with a dominator coloring.

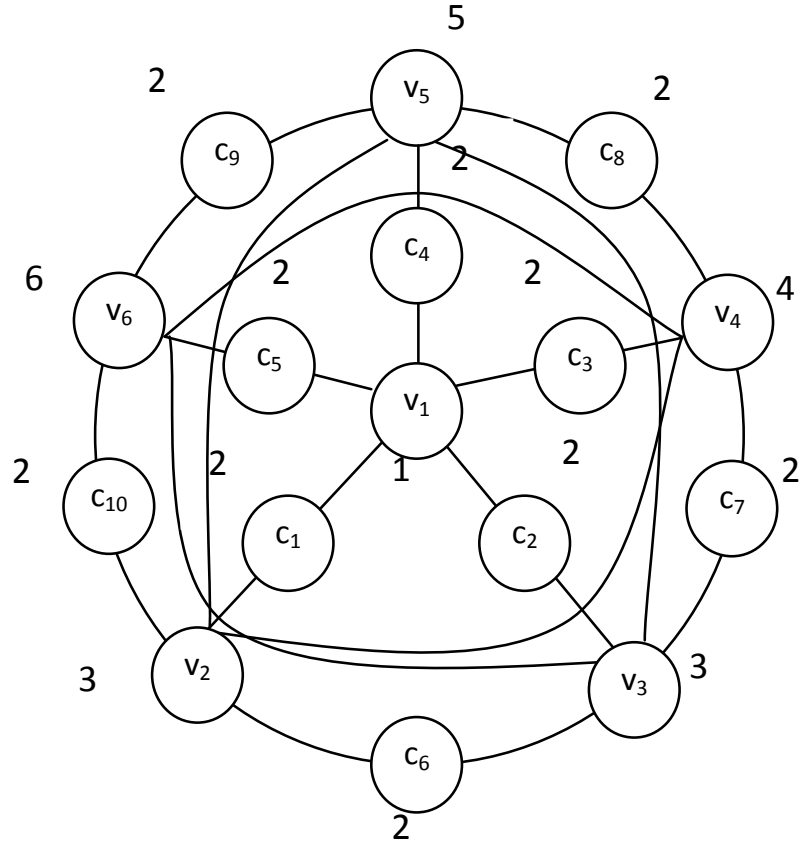

Figure 3

The color classes of $\mathrm{C}\left(\mathrm{W}_{1}, 5\right)$ are, $\mathrm{V}_{1}=\left\{\mathrm{v}_{1}\right\}$, $\mathrm{V}_{2}=\left\{\mathrm{c}_{1}, \mathrm{c}_{2}, \mathrm{c}_{3}, \mathrm{c}_{4}, \mathrm{c}_{5}, \mathrm{c}_{6}, \mathrm{c}_{7}, \mathrm{c}_{8}, \mathrm{c}_{9}, \mathrm{c}_{10}\right\}, \mathrm{V}_{3}=\left\{\mathrm{v}_{2}, \mathrm{v}_{3}\right\}$, $\mathrm{V}_{4}=\left\{\mathrm{v}_{4}\right\}, \mathrm{V}_{5}=\left\{\mathrm{v}_{5}\right\}$ and $\mathrm{V}_{6}=\left\{\mathrm{v}_{6}\right\}$. The dominator chromatic number is, $\chi_{\mathrm{d}}\left[\mathrm{C}\left(\mathrm{W}_{1,5}\right)\right]=6$.

\section{Theorem 2.7}

For complete graph $\mathrm{K}_{\mathrm{n}}$ of order $\mathrm{n} \geq 3$, $\chi_{\mathrm{d}}\left[\mathrm{C}\left(\mathrm{K}_{\mathrm{n}}\right)\right]=\mathrm{n}+1$.

\section{Proof}

Let $K_{n}$ be the complete graph of order $n \geq 3$ and let $\mathrm{V}\left(\mathrm{K}_{\mathrm{n}}\right)=\left\{\mathrm{v}_{1}, \mathrm{v}_{2}, \ldots, \mathrm{v}_{\mathrm{n}}\right\}$. The central graph is obtained by subdividing each edge $\mathrm{v}_{\mathrm{i}} \mathrm{v}_{\mathrm{j}}$ exactly once by the center vertex $\mathrm{c}_{\mathrm{ij}}, 1 \leq \mathrm{i}, \mathrm{j} \leq \mathrm{n}, \mathrm{i} \neq \mathrm{j}$. Let $\mathrm{v}_{1}=\left\{\mathrm{v}_{1}, \mathrm{v}_{2}, \ldots, \mathrm{v}_{\mathrm{n}}\right\}$ and $\mathrm{V}_{2}=\left\{\mathrm{c}_{\mathrm{ij}} / 1 \leq \mathrm{i}, \mathrm{j} \leq \mathrm{n}, \mathrm{i} \neq \mathrm{j}\right\}$. Then $\mathrm{V}\left(\mathrm{C}\left(\mathrm{K}_{\mathrm{n}}\right)\right)=\mathrm{V}_{1} \cup \mathrm{V}_{2}$.

A dominator coloring of $\mathrm{C}\left(\mathrm{K}_{\mathrm{n}}\right)$ is obtained by the following procedure. Since the center vertices form an independent set, color $\mathrm{c}_{\mathrm{ij}}, 1 \leq \mathrm{i}, \mathrm{j} \leq \mathrm{n}, \mathrm{i} \neq \mathrm{j}$, by color 1 . The vertex $\mathrm{v}_{\mathrm{i}}$ is colored by the color $(\mathrm{i}+1), 1 \leq \mathrm{i} \leq \mathrm{n}$.

The center vertex $\mathrm{c}_{\mathrm{i}}, 1 \leq \mathrm{i} \leq \mathrm{n}$ dominates at least one of the color classes of $v_{i}, 1 \leq i \leq n$. The vertices $v_{1}, v_{2}, \ldots, v_{n}$ dominate themselves. Hence $\chi_{d}\left[C\left(K_{n}\right)\right]=n+1$. 


\section{Theorem 2.8}

For complete bipartite graph $\mathrm{K}_{\mathrm{m}, \mathrm{n}}$ of order $\mathrm{m}, \mathrm{n} \geq 1$, $\chi_{\mathrm{d}}\left[\mathrm{C}\left(\mathrm{K}_{\mathrm{m}, \mathrm{n}}\right)\right]=\mathrm{m}+\mathrm{n}$.

\section{Proof}

Let $\left\{\mathrm{v}_{\mathrm{i}}: 1 \leq \mathrm{i} \leq \mathrm{m}\right\}$ and $\left\{\mathrm{u}_{\mathrm{j}}: 1 \leq \mathrm{j} \leq \mathrm{n}\right\}$ be the vertices of $\mathrm{K}_{\mathrm{m}, \mathrm{n}}$ and by the definition of complete bipartite graph , every vertex in $\left\{\mathrm{v}_{\mathrm{i}}: 1 \leq \mathrm{i} \leq \mathrm{m}\right\}$ is adjacent to every vertex in $\left\{\mathrm{u}_{\mathrm{j}}: 1 \leq \mathrm{j} \leq \mathrm{n}\right\}$. Let $\left\{\mathrm{e}_{\mathrm{ij}}: 1 \leq \mathrm{i} \leq \mathrm{m}\right.$ and $\left.1 \leq \mathrm{j} \leq \mathrm{n}\right\}$ be the set of edges of $K_{m, n}$. By the definition of central graph, each edge $\mathrm{e}_{\mathrm{ij}}$ for $1 \leq \mathrm{i} \leq \mathrm{m}$ and $1 \leq \mathrm{j} \leq \mathrm{n}$ is subdivided by a vertex $\mathrm{c}_{\mathrm{ij}}$ in $\mathrm{C}\left(\mathrm{K}_{\mathrm{m}, \mathrm{n}}\right)$ and let $\mathrm{V}=\left\{\mathrm{v}_{1}, \mathrm{v}_{2}, \ldots, \mathrm{v}_{\mathrm{m}}\right\}, \mathrm{V}^{\prime}=\left\{\mathrm{u}_{1}, \mathrm{u}_{2}, \ldots, \mathrm{u}_{\mathrm{n}}\right\}$ and $\mathrm{V}^{\prime \prime}=\left\{\mathrm{c}_{\mathrm{ij}} / 1 \leq \mathrm{i} \leq \mathrm{m}, 1 \leq \mathrm{j} \leq \mathrm{n}\right\}$. Clearly $\mathrm{V}\left(\mathrm{C}\left(\mathrm{K}_{\mathrm{m}, \mathrm{n}}\right)\right)=\mathrm{V} \cup \mathrm{V}^{\prime} \cup \mathrm{V}^{\prime \prime}$. Note that in $\mathrm{C}\left(\mathrm{K}_{\mathrm{m}, \mathrm{n}}\right)$, the induced subgraphs $\left\langle\mathrm{V}=\left\{\begin{array}{llll}\mathrm{v}_{1}, & \mathrm{v}_{2}, & \ldots, & \mathrm{v}_{\mathrm{m}}\end{array}\right\}\right\rangle$ and $\left\langle\mathrm{V}^{\prime}=\left\{\mathrm{u}_{1}, \mathrm{u}_{2}, \ldots, \mathrm{u}_{\mathrm{n}}\right\}\right\rangle$ are complete.

The following procedure gives a dominator coloring of $\mathrm{C}\left(\mathrm{K}_{\mathrm{m}, \mathrm{n}}\right)$. The set of vertices $\left\{\mathrm{c}_{\mathrm{ij} /}, 1 \leq \mathrm{i} \leq \mathrm{m} ; 1 \leq \mathrm{j} \leq \mathrm{n}\right\}$ is independent and hence assign the color 1 to these vertices. The vertices $v_{1}$ and $u_{1}$ are non-adjacent in $C\left(K_{m, n}\right)$ and therefore they are colored by color 2 . As the induced subgraphs $\langle\mathrm{V}\rangle$ and $\left\langle\mathrm{V}^{\prime}\right\rangle$ are complete, the vertex $\mathrm{v}_{\mathrm{i}}$ is colored by the color $(\mathrm{i}+1), 2 \leq \mathrm{i} \leq \mathrm{m}$ and the vertex $\mathrm{u}_{\mathrm{j}}$ is colored by the color $(\mathrm{m}+\mathrm{j}), 2 \leq \mathrm{j} \leq \mathrm{n}$

The vertex $\mathrm{v}_{1}$ dominates the color classes of $\mathrm{v}_{\mathrm{i}}$, $2 \leq \mathrm{i} \leq \mathrm{m}$ and the vertex $\mathrm{u}_{1}$ dominates the color classes of $\mathrm{u}_{\mathrm{j}}$, $2 \leq \mathrm{j} \leq \mathrm{n}$. The vertices $\mathrm{v}_{\mathrm{i}}$ and $\mathrm{u}_{\mathrm{j},} 2 \leq \mathrm{i} \leq \mathrm{m} ; \mathrm{u}_{\mathrm{j}}: 2 \leq \mathrm{j} \leq \mathrm{n}$ dominate themselves. The center vertex $c_{i j}$ dominates one of the color classes of $\mathrm{v}_{\mathrm{i}}$ and $\mathrm{u}_{\mathrm{j}}, 2 \leq \mathrm{i} \leq \mathrm{m} ; \mathrm{u}_{\mathrm{j}}: 2 \leq \mathrm{j} \leq \mathrm{n}$. Hence $\chi_{\mathrm{d}}\left[\mathrm{C}\left(\mathrm{K}_{\mathrm{m}, \mathrm{n}}\right)\right]=\mathrm{m}+\mathrm{n}$.

By combining the observations of [2] and above theorems, we have the following result.

\section{Result 2.9}

(i)

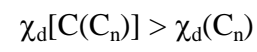

$$
\chi_{\mathrm{d}}\left[\mathrm{C}\left(\mathrm{P}_{\mathrm{n}}\right)\right]>\chi_{\mathrm{d}}\left(\mathrm{P}_{\mathrm{n}}\right)
$$

$$
\chi_{\mathrm{d}}\left[\mathrm{C}\left(\mathrm{W}_{1, \mathrm{n}}\right)\right]>\chi_{\mathrm{d}}\left(\mathrm{W}_{1, \mathrm{n}}\right)
$$

(iv) $\quad \chi_{\mathrm{d}}\left[\mathrm{C}\left(\mathrm{K}_{\mathrm{n}}\right)\right]>\chi_{\mathrm{d}}\left(\mathrm{K}_{\mathrm{n}}\right)$

\section{CONCLUSION}

In this paper, we obtained the dominator chromatic number of central graph of various graph families are obtained and compared with dominator chromatic number of their corresponding graph families. This paper can further be extended by identifying graph families of graphs for which these chromatic numbers are equal to other kinds of chromatic numbers.

\section{ACKNOWLEDGMENTS}

The authors wish to thank the referee and the Editor-in-Chief for their encouragements and helpful suggestions and comments to improve this paper.

\section{REFERENCES}

[1] J. A. Bondy and U.S.R. Murty, Graph theory with Applications, London: MacMillan (1976).

[2] R.M. Gera, On Dominator Colorings in Graphs, Graph Theory Notes of New York LIT, 25-30 (2007)

[3] F. Harary, Graph Theory, Narosa Publishing 1969.

[4] D. Michalak, On Middle and Total graphs with Coarseness Number Equal 1, Lecture Notes in Mathematics, Volume 1018: Graph Theory, SpringerVerlag, Berlin, 139 - 150 (1983). 